\title{
FORENSIC DENTISTRY
}

\author{
Brigadier D. V. TAYLOR, C.B.E., F.D.S.(Eng.), F.D.S.(Edin.), Barrister-at-Law \\ Royal Army Medical College, Millbank*
}

\section{Introduction}

Perhaps the most acceptable definition of Forensic Dentistry, or Forensic Odontology as it is termed in some countries, is "The application of dental knowledge to the elucidation of legal problems" taken in the widest sense. As a science it is still in its infancy, but considerable advances have taken place in recent years and today it is true to say that it is rapidly becoming a small but important part of forensic medicine.

\section{Historical Development}

Until quite recently little had been done to organise a system of applying dental knowledge and expertise to the solution of forensic problems nor had the subject, or that of dental jurisprudence, been included in the syllabus of teaching schools or been given much consideration in the research field. Dentists had been called in from time to time by the police and by forensic pathologists to lend their aid, but as Gustafson (1958) wrote " those of us who deal with these problems are amateurs who dabble a little as occasion arises".

Nevertheless the first comprehensive treatise on the subject was published in Paris as early as 1898 (Amoedo, 1898) and its distinguished author has since become known as "the father of forensic odontology". Even before that year a number of cases in which dentists played an important role had been reported. Of these the best known was that of the murderer Dr. Webster, a professor at Harvard University in 1849. Webster was convicted of murdering a colleague, a Dr. Packman, largely on the evidence of a dentist who showed that some remnants of a denture which were found amongst the charred human remains in Webster's laboratory furnace were part of a prosthesis he had previously supplied to the victim, Dr. Packman.

Between 1940 and 1950 there were several celebrated murder trials in which dentists figured prominently.

In R. v. Dobkin (1942), the famous ' Baptist Church Cellar Case', the wife of one Dobkin, a fire-watcher, had disappeared at about the same time as the police had remarked on the suspicious behaviour of her husband when a fire broke out in the Kensington Baptist Church. When, a year later, a partially burnt and dismembered human body was dug up at the site of this fire it was identified as being that of Mrs. Dobkin from the dental records obtained from her dentist, in which the noted presence of two buried roots was particularly helpful.

In the cases of both R. v. Heath 'the Bournemouth murderer' and R. v. Gorringe the murdered women were found to have bite marks on their breasts. In his report on the latter Simpson (1951) described how models of her husband's teeth showed them to be " badly spaced, angled, and curiously shaped" and how they were found to fit the bitemarks in the tissues.

In R. v. Haigh (1949) complete upper and lower dentures were recovered from the

* Now Amalgamated Dentai Company Ltd., London. 
sludge resulting from the dissolution of a human body by immersion in sulphuric acid. From these the identity of the victim was established.

Since these isolated incidences there has been a rapid increase of interest and activity in forensic dental science. In some Scandinavian countries, dental experts now form part of identification teams. Chairs of forensic odontology have been established in some of the teaching schools, study courses organised, and a great deal has been done to promote accurate dental record keeping, particularly for personnel at above average risk, for example, airline and shipping crews and servicemen (Fig. 1).

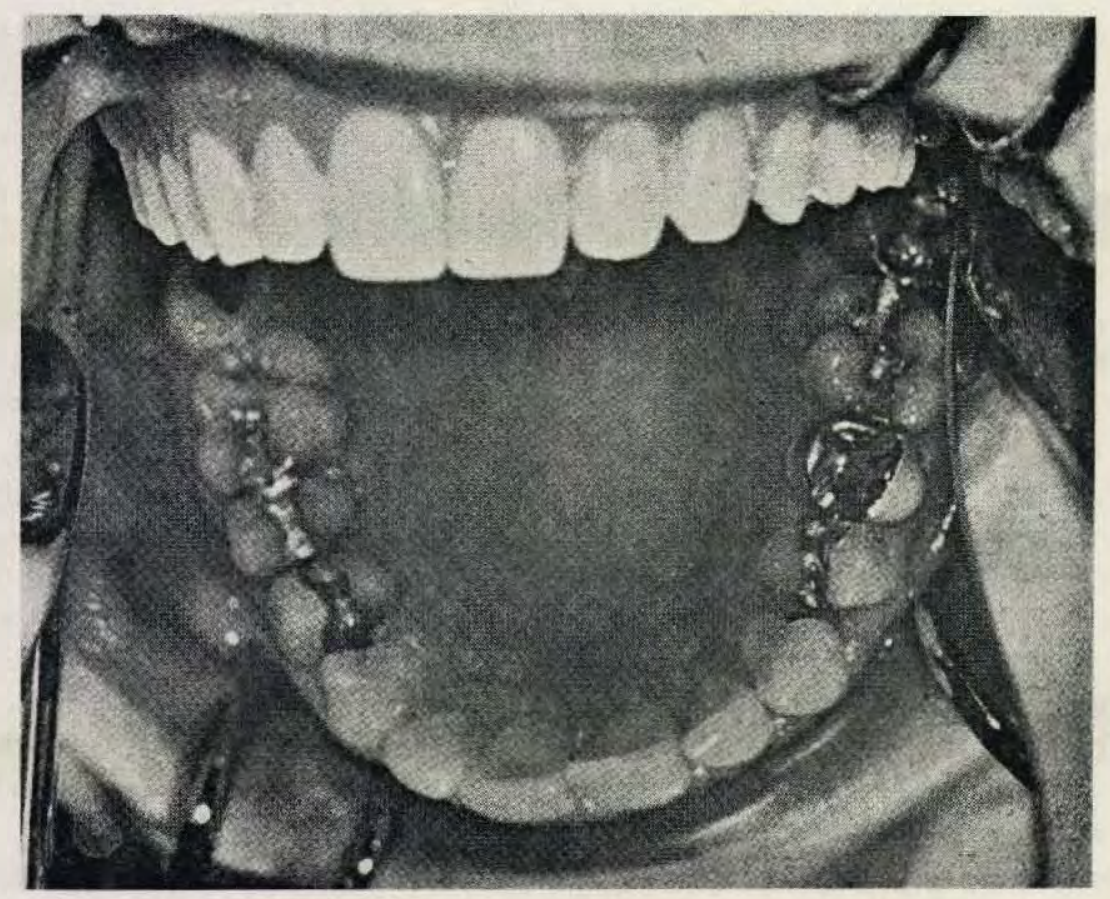

Fig. 1 -Dental condition recorded by standard photograph.

In this country dentists are being called in more and more frequently to assist in forensic investigations, and there is an increasing number of articles on the subject appearing in the professional journals. As yet, however, only a few enthusiasts are devoting what time they can to study and research in the field and the schools are only just beginning to recognise the subject as one worthy of investigation and teaching. However, 1966 saw the publication in English in this country of the latest and most authoritative and comprehensive work (Gustafson, 1966) yet to be produced on forensic odontology and this will no doubt quicken the interest which was already being shown in it.

\section{Present Scope and Application}

Identification from previous records

By far the main application of dental science in the forensic field is to the identification of human remains, but although less frequently required, proof of the identity of 
living persons by dental means sometimes assumes considerable importance in criminal. cases.

Investigations undertaken with these objects in view must usually make use of, and indeed depend largely on existing dental records. Most of the more advanced countries have such records available and, since the inception of the National Health Service, this country has been fortunate in possessing reasonably accurate dental data on a large section of the population, preserved centrally at least for a limited period. Nevertheless, it is the possible lack of precise and accurate dental data which may defeat the forensic dentist.

However, when such are available, it is now fully recognised that there is presented in most cases an array of facts in sufficient number and individual detail as to be possible of application to but one individual. The dental record can give unequivocal information on not only the dental state by means of a chart, but also of the treatment history, including details of the materials used, of dentures supplied and of many other oral conditions concerning possibly development or pathology. All these facts taken collectively can easily become conclusive evidence.

Fortunately, for various reasons, the dental tissues together with the materials used for their repair and replacement are more likely to remain intact in situ than other parts of a human body which has been subjected to mutilation, incineration, or disintegration by water or chemicals. The dental structures are situated in a relatively protected environment-the mouth-the materials used in dental treatment are often high fusing metals or porcelain, or tough resistant cements, and the teeth roots, embedded in the alveolar bone, are often found still in place undamaged ready to yield valuable information on X-ray examination.

Of the importance of establishing the identity of the dead for legal and humanitarian reasons, and the living to promote justice in criminal or civil courts, there can be no doubt. Modern forms of transport and travel, and modern warfare frequently pose problems of identification of unrecognisable human remains, when clothes and personal possessions have been lost or destroyed, and identification marks including the surface markings on finger and thumb obliterated.

Such problems become even more difficult when identification is required of a number of corpses, a situation which is occurring with increasing frequency in these days when aircraft, train and bus crashes, multiple car accidents and engulfment of buildings by avalanches and earth movements seem to follow each other at even shorter intervals. In mass disasters of this sort the problem becomes one not only of positive identification but also of the negative reverse and requires the use of some type of elimination chart on which the names of the known missing persons can be matched against the unidentified bodies until all possible identities have been established (Fig. 2).

\section{Identification from Bite Marks}

Clearly-showing bite marks can sometimes be used by a dentist who has the requisite knowledge of, and training in, the technical requirements involved, to identify the person who made them. Bite marks show up well in depth in certain foodstuffs, especially butter, cheese and chocolate, and impressions can be obtained from these for comparison with models of the teeth of individuals suspected of producing them (Fig. 3).

On the other hand, when human tissues are bitten, the marks are usually little in- 


\begin{tabular}{|c|c|c|c|c|c|c|c|c|}
\hline $190 \mathrm{KT} .169$ & \begin{tabular}{c|c|c|c|} 
& \\
-12 & -1
\end{tabular} & $19\left|\begin{array}{c}c \\
-1\end{array} \cdot-2\right|-11$ & & & $-n$ & & & \\
\hline \multicolumn{9}{|l|}{ J.DOERING } \\
\hline \multicolumn{9}{|l|}{ J.M.THOMAS } \\
\hline \multicolumn{9}{|l|}{ R.ZIMMERMAN } \\
\hline \multicolumn{9}{|l|}{ H.H.KOHN } \\
\hline \multicolumn{9}{|l|}{ T.J.MALLOY } \\
\hline \multicolumn{9}{|l|}{ D.KEOOIE } \\
\hline \multicolumn{9}{|l|}{ C. BELTZHOOVER } \\
\hline \multicolumn{9}{|l|}{ M. BERKE } \\
\hline \multicolumn{9}{|l|}{ L.H.BLAKE } \\
\hline \multicolumn{9}{|l|}{ J.L.CALIHAN } \\
\hline \multicolumn{9}{|l|}{ B.FUREY } \\
\hline \multicolumn{9}{|l|}{ F.S. JEWELL } \\
\hline \multicolumn{9}{|l|}{ A.LEYBOURN } \\
\hline \multicolumn{9}{|l|}{ W.J.PASCOE } \\
\hline A.PRICE & & & & & & & & \\
\hline
\end{tabular}

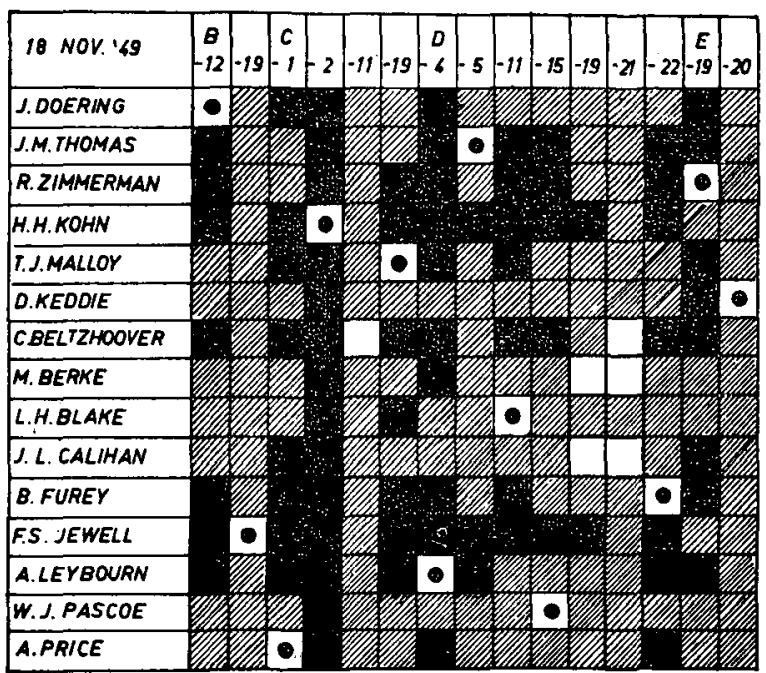

Fig. 2-Elimination charts as used by Grant, Prendergast and White (1952). Male bodies and male missing persons. The upper chart shows the situation on the 19 Oct. with black squares showing dental elimination. The lower chart (18 Nov.) shows all cases identified except three, which were later identified. Redrawing from Pederson and Keiser-Neilson (1960).

Reproduced from Forensic Odontology, by Gosta Gustafson, by kind permission of Staples Press, London.

dented and may be but poorly defined bruises. On occasion, however, it may be possible to fit a model into the marks on the skin, or these may be sufficiently well outlined as to permit a satisfactory comparison with the incisal edges of the teeth on a model; there have been several cases, one of which has been quoted previously, in which evidence obtained from such marks has been of major importance (Figs 4 \& 5).

\section{Age determination}

During the period of tooth development, age can be estimated with reasonable accuracy, by comparing the dental state with a diagrammatic table of tooth chronology 


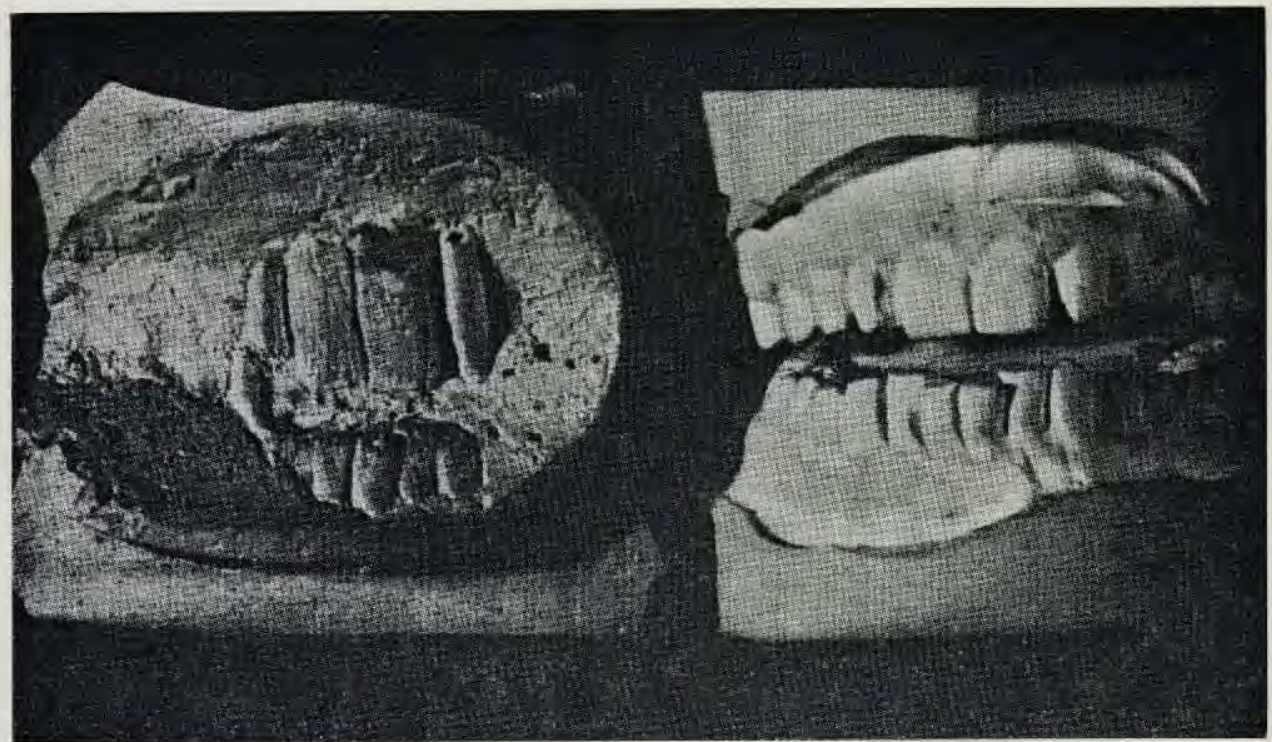

Fig. 3-Plaster model of bite-marks in margarine with models of the teeth which made the marks. Reproduced from Tandlaegebladet, No. 1, January, 1932 by kind permission of the Danish Dental Association.

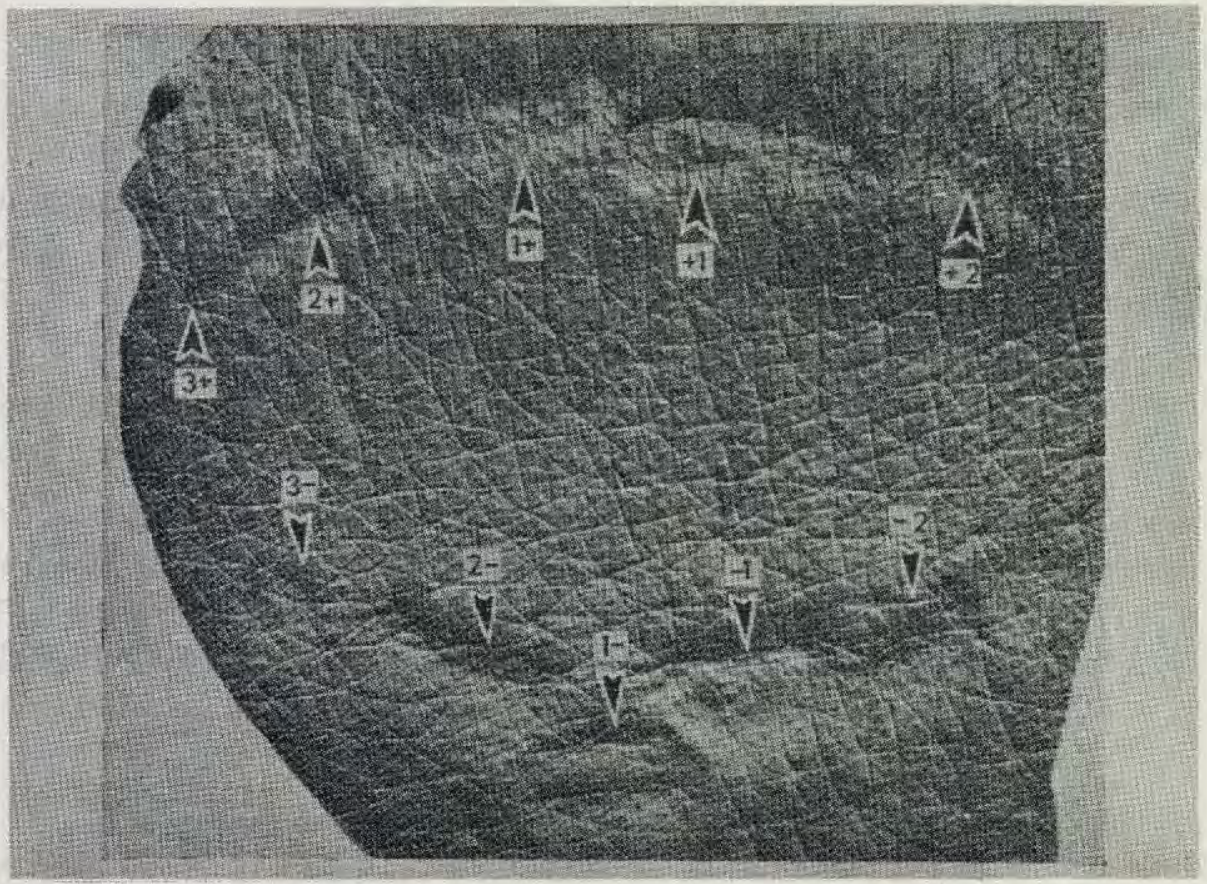

Fig. 4 Impression of bite marks in the arm. The indentations are very shallow and practically only visible on this photograph of the impression.

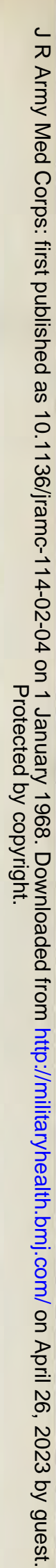




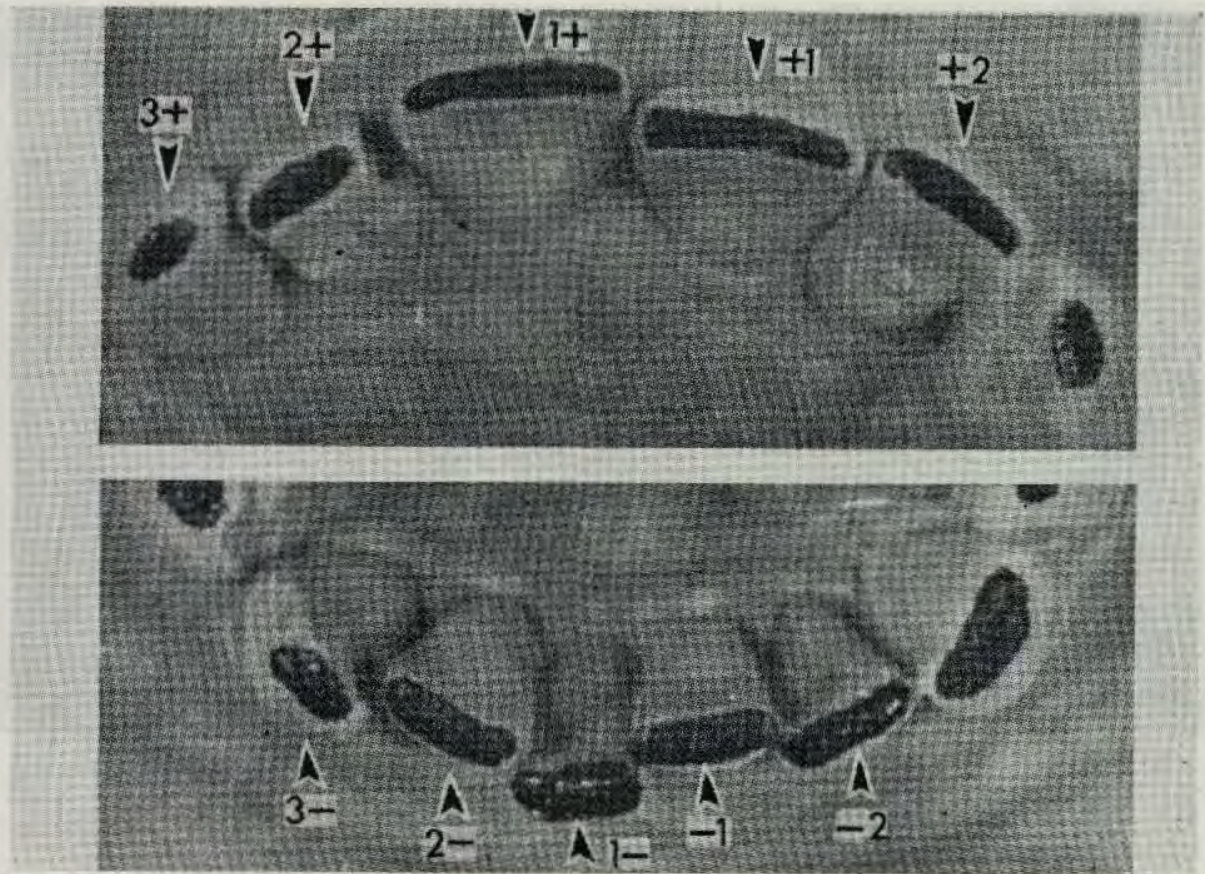

Fig. 5-The front teeth of the person who made the bite. There is complete agreement between the position of the bite-marks and of the teeth on the model.

Figs 4 and 5 reproduced from Forensic Odontology, by Gosta Gustafson, by kind permission of Staples Press, London.

such as that of Schour and Massler (1940). The value of this method diminishes, however, from the age of twelve years onwards, and becomes more or less useless after the age of twenty years, when the factors of eruption and calcification of teeth cease to apply.

To augment this relatively simple procedure and to expand the range during which age estimation may be attempted, a number of ingenious methods and formulae have been put forward. These are mostly based on various known age changes in the teeth and supporting structures. Some involve a quantatitive consideration of the degree of attrition of the teeth, of the deposition of secondary dentine and cementum, of the degree of translucency and absorbtion of the tooth roots and of changes in the paradontal tissues.

\section{Other evidence}

In addition to the above, a dental scientist with special knowledge and training may be able, from a dental examination, to give a firm opinion on the probable sex and race of a dead person and on the likely occupation, habits and social position of the deceased.

\section{Service Application}

During the past two years the Armed Forces Dental Services Commission of the International Dental Federation has been giving much thought to the possibility of augmenting the present means of identification of military personnel by dental evidence. Replies to a questionnaire from 45 Dental Services (from 36 different countries) have revealed that 25 ( 56 per cent.) make provisions for identifying casualties by dental means, 
that no less than 17 (in 11 countries) including the three British Services carry out a system of denture marking and that 22 keep special dental records of personnel at above average risk in peacetime. It must be realised, however, that any system is of limited value until it is co-ordinated on an international basis with those of as many other countries as possible and international co-operation on this matter is essential.

There have been several cases in recent years when officers of the Army Dental Service have been able to give valuable aid in matters of identification. One such was in the recent Aberfan disaster (Knott, 1967) and another of considerable technical interest occurred during the Suez campaign (Taylor, 1963).

\section{Conclusion}

It must now be accepted that the scope of modern forensic dentistry is such as to require a dentist who wishes to engage in its practice to acquire specialised knowledge and experience and to have available to him the facilities, when occasion demands, of a pathology and science laboratory and a photographic department. In some countries the need for dental forensic experts based on dental teaching schools has been recognised and implemented. No doubt in the years to come more of these appointments will be made. No less an authority than Simpson (1951) now Professor of Forensic Medicine in the University of London, foreshadowed such a possibility when he wrote "Dental data, it is now realised, have come to provide detail of a kind comparable with the infinitesimal detail that was previously thought likely to be provided only by finger printsa reason for coming to regard teeth as of the very greatest importance in the identification of an individual ".

\section{REFERENCES}

FRY, W. K. (1943). Brit. dent. J. 75, 154.

Gustafson, G. (1958). Proc. roy. Soc. Med. 51, 1044.

KNOTT, N. J. (1967). Brit. dent. J. 122, 144.

Schour, I. and Massler, M. (1940). J. Amer. dent. Ass. 27, 1918.

SiMPSON, K. (1951). Brit. dent. J. 91, 229.

TAYLOR, D. V. (1963). Brit. dent. J. 144, 389.

\section{BIBLIOGRAPHY}

Forensic Odontology (1966). Gustafson, G. Staples Press, London.

L'Art Dentaire en Medecine Legal (1898). AMOEDo, O. Massou et Cie, Paris.

\section{ACADEMIC ACHIEVEMENTS}

M.R.C.P.(Lond.)
M.C.Path

D.C.Path

F.F.A.R.C.S.

D.I.H.

D.A.

M.R.C.O.G.
Captain D. R. BeVan, B.chir., R.A.M.C.

MAJOR D. M. WAYTE, M.B., Ch.B., M.R.C.S., L.R.C.P., D.T.M.\&H., D.Path., R.A.M.C.

MAJOR J. B. STEWART, M.B., Ch.B., D.T.M.\&H., R.A.M.C.

CAPTAIN N. J. BURBRIDGE, M.B., B.S., M.R.C.S., L.R.C.P., D.T.M.\&H., R.A.M.C.

MAJOR I. P. CRAWFORD, G.M., M.R.C.S., L.R.C.P., D.T.M.\&H., D.P.H., R.A.M.C.

CAPTAIN G. HARRIS, M.B., B.S., M.R.C.S., L.R.C.P., R.A.M.C.

CAPTAIN (Miss) H. B. HANNAH, M.B., Ch.B., R.A.M.C.

MAJOR M. B. A. JACKSON, M.B., B.S., M.R.C.S., L.R.C.P., D.obst.R.C.O.G., D.T.M.\&H., R.A.M.C. 